\title{
Impact of Speculation and Bubble Detection in Stock Markets: The Tunisian and the Moroccan Cases
}

\author{
Bassem Salhi $^{1} \&$ Saad Alflayyeh ${ }^{1}$ \\ ${ }^{1}$ College of Business Administration, University of Majmaah, Saudi Arabia \\ Correspondence: Bassem Salhi, Assistant Professor, PhD Finance and Accounting, College of Business \\ Administration, University of Majmaah, Saudi Arabia.
}

Received: April 26, 2016

Accepted: May 14, 2016

Online Published: May 17, 2016

doi:10.5430/jms.v7n2p73

URL: http://dx.doi.org/10.5430/jms.v7n2p73

\begin{abstract}
The past few years have seen an unprecedented increase in speculative activities. While the exact tools remain controversial, the negative impact is not doubtful. This thesis attempts to explain speculation, what it actually is and what it is not.

In this paper we seek to identify periods of mildly explosive or bubble-like, behaviour of the Tunisian market during the period 2004 to 2014. We do so on one hand using STATA's rolling and recursive estimation techniques on the Tunisian stock market price index (TUNINDEX) then, we compare it to the Moroccan Index (MASI), On the other hand we apply the same testing procedure on 4 Big companies of the Tunisian market.

These tests help detecting if prices deviate from a random walk and become mildly explosive since as stipulated above, the identification of explosive characteristics in the price is equivalent to the detection of stock bubble.
\end{abstract}

Keywords: speculation, bubble detection, stock market, Tunisian market, Moroccan market

\section{Introduction}

Nonetheless when not acting carefully investors could drive prices away from fundamental values, thus causing what we refer to as a "bubble". A bubble can be defined theoretically and in the simplest way as sustained price deviations from its fundamental value. There has emerged a growing literature on how one can spot bubbles. Studies on financial speculation and bubbles are on vogue today. Recently stock markets of the whole word -Tunisia included -reached its highest level in history, one cannot help but question about whether this steep rise is a sign of a promising economic growth or in fact a bubble in disguise.

How does one tell when rapidly increasing prices are caused by fundamental factors of supply and demand, and when it is merely a bubble?

To this end we seek in this paper to examine empirically the Tunisian market's performance trying to detect the existence or not of such an exuberance behavior in the TUNINDEX (Tunisian stock Index).

\section{Getting to Know Speculation}

\subsection{Defining Speculation}

The U.S. Commodity Futures Trading Commission defines a speculator as a trader who does not hedge, but who trades with the objective of achieving profits through the successful anticipation of price movements.

Seeing that these traders will take positions in the market based on their anticipation of future prices it is only fair to agree with Keynes who defines speculation as the activity of forecasting the psychology of the market.

Harrison and Kreps (1978) define speculation as follows: "An investor may buy the stock now, so as to sell it later for more than he thinks it is actually worth, thereby reaping capital gains". So it is simply buying when the price is low if expecting it to likely go up in the future and selling when the price is high and so reap gain from the difference between the selling and the purchasing price, this need buyers and sellers with different views. Speculation is therefore as Martin Frisdson (1993) puts it "a fair term for attempts to exploit pricing anomalies" 
This operation of speculating covers a wide range of trading tactics, including pairs trading, swing trading, employing hedging strategies. Speculators are often skilled at fundamental analysis, including spotting over or under-valued companies. It could also take place via over the counter market and Derivatives.

This vision is also shared by some recent studies such as Brunetti and al. (2011) and Deuskar and Johnson (2011), which have found that speculative activity reduces market volatility and illiquidity without leading to any price changes.

For Bernardina Algieri (2012), the difference between speculation and excessive speculation should be considered the bridge that could combine the traditional and non-traditional speculative theories.

\subsection{Defining Bubbles}

Ahamed (2009): "Financial booms and busts were, and continue to be, a feature of the economic landscape. These bubbles and crises seem to be deep-rooted in human nature and inherent to the capitalist system. By one count there have been 60 different crises since the $17^{\text {th }}$ century".

The definition of one can sometimes appear slightly hazy; Kindleberger (1987) for instance defined bubble as a sharp and continuous rise in price of an asset or a range of assets. In the financial context, the term generally refers to a situation where the price for an asset exceeds its fundamental value by a large margin.

Actually, it can manifest in many different contexts and within different asset classes, however all bubbles share the same characteristics. We will be referring to Alvaro Jiménez's (2011) paper "understanding bubbles" for this matter.

First they all come with a supreme rise in prices usually in a really short period of time leading to Zero correlation with fundamental value. In other words, price will no more reflect the true value of stocks and the bubble is what represents this deviation of the current market price of the asset from the value implied by market fundamentals.

The second characteristic is massive investment/speculation which is the reason behind this price rise. This massive speculation results in a flow of great deal amounts of money towards one focus in order to generate the bubble.

Third factor is about the common context in the formation of a bubble, where with promising venture comes uncertainty about the projects to be undertaken, their feasibility, their profitability, and even their future demand.

The fourth characteristic is leverage, either through margin purchases, simple down payments, derivatives, or abundance of credit and debt, leverage is found among agents participating in the bubble process.

Last but not least, the government role is not to be neglected. In almost each bubble respective governments directly or indirectly took part in various stages of the bubble if not at every stage. It could be through fiscal incentives, monetary policy or others...

\section{Empirical Study}

\subsection{Literature Review}

Enormous increases in stock prices followed by crashes have led many researchers to test for the presence of speculative bubbles. Among these are Shiller (1981) and Leroy and Porter (1981), who proposed variance bounds tests, West (1987), who designed a two-step test for bubbles, and Froot and Obstfeld (1991), who considered intrinsic bubbles. While Phillips, $\mathrm{Wu}$, and $\mathrm{Yu}(2011)$ used sequential unit-root tests.

Nonetheless a number of studies (e.g., Robert J. Shiller, 1981; Olivier J. Blanchard and Mark Watson, 1982; Kenneth D. West, 1988) have argued that dividend and stock price data are not consistent with the "market fundamentals" hypothesis, in which prices are given by the present discounted values of expected dividends.

Behzad T. Diba and Herschel I. Grossman $(1984,1988 b)$ tested for bubbles by checking whether the stock price is more explosive than the dividend process and argued against the existence of bubbles in the S\&P 500.

Hamilton and Whiteman (1985) have recommended the alternative strategy of testing for rational bubbles by investigating the stationarity properties of asset prices and observable fundamentals. In essence, the argument for equities is that if stock prices are not more explosive than dividends then it can be concluded that rational bubbles are not present,

Evans (1991) demonstrates that Diba and Grossman's (1988) tests do not have sufficient power to effectively detect bubbles that collapse periodically. Phillips and al (2011) also propose to use sequences of Dickey-Fuller statistics to estimate the date of the emergence of a bubble, i.e. to estimate the date of a regime switch from a random walk to an explosive process. 


\subsection{Methodology}

In this paper we will be following the setup in Phillips and al (2007, and 2011) which stipulates that in the rational bubble literature, if bubbles are present, they should manifest explosive characteristics in prices.

In econometric terms, boom-bust cycles in asset markets can best be analyzed using changing-stationarity models that study changes from stationary process to unit root or even to explosive process, as shown by Phillips and al (2011) and then back to stationary process.

In this paper we seek to identify periods of mildly explosive or bubble-like, behaviour of the Tunisian market during the period 2004 to 2014. We do so on one hand using STATA's rolling and recursive estimation techniques on the Tunisian stock market price index TUNINDEX. Then, we compare it to the Moroccan Index MASI, On the other hand we apply the same testing procedure on 4 Big companies of the Tunisian market.

These tests help detecting if prices deviate from a random walk and become mildly explosive since as stipulated above, the identification of explosive characteristics in the price is equivalent to the detection of stock bubble.

The convenient empirical approach here is to identify bubbles by applying statistical tests for a structural change from a random walk to a stationary or explosive regime. To this end the simplest version is to test referring to a first order autoregressive process.

$$
X_{t}=\mu_{t}+\rho X_{t-1}+\varepsilon_{x, t}
$$

Where for certain sub periods of the data $\rho>1$. Figure 1 in the appendix shows typical time series plots for stationary $\rho=0,8$ random walk $\rho=1$ and explosive $\rho=1,03$ processes with intercept $\mu=0$.

The differences in the trajectories are apparent and useful to help us understand what is different between a stationary process and a bubble process.

Under the null hypothesis, the price follows a random walk for all time periods, under the right sided alternative hypothesis, the process starts as a random walk but changes to an explosive process at an unknown time.

- H0: $\rho=1$, unit root process: random walk: non-stationary time series; No bubble

- H1: $\rho>1$, right tailed process: explosive process; Bubble exist

The key point to note is that the previous Dickey Fuller distributions are skewed to the left with respect to the standard normal distribution.

Therefore in this case when the statistics exceed the critical value (CV) we reject the null Hypothesis of unit root in favour of explosive behaviour for the index.

\subsubsection{Data Description}

To investigate the TUNISIAN stock market:

- In first place we will be working on Monthly observations of TUNINDEX and daily observation of MASI, Our sample covers the period from January 2004 to October 2014 and comprises 131monthly observation for TUNINDEX and 2716 daily observation for MASI.

- In second place we will be examining the behavior of 4 listed companies by working on their dividend Yield and daily observation from January 2009 to December 2013.

The data are obtained from the official website of the Tunisian stock market and essentially from lboursa.com; the new gate for the Tunisian stock market.

These time series are all transformed to log form to smooth the series.

\subsubsection{Rolling Analysis}

The ADF statistic is computed for a rolling subsample. These samples would be fixed in length but would update and roll forward one step (observation) at a time, adding one observation to the end of the sample and dropping the first observation from the sample. For example, if your dataset has values on a time series with 200 observations and you want to perform rolling regression, the idea is to start with an initial window of a fixed width say 40 values it will include the observations from the first observation 1 to the 40th observation, perform the ADF test and then roll the window, the second window of data would be the next 40 observations starting from the 2 nd observation (2nd to the 41 st observation). The third window will be the next 40 values starting from the 3 rdth value, and so on. Similarly, for each of the following subsample we just move the subsample forward by one observation but keep the size fixed at 40. Thus, every subsample has the same size. 
This technique help detecting changing property of a series over time by offering an estimate of the property over time instead of one single constant measure for the entire period. We can also plot those estimates over time to see if they are variable or stabilizing.

\subsubsection{Recursive Analysis}

The recursive ADF (also referred to as Sup ADF) test is as indicated by its name, based on recursive calculations of the ADF statistic with an expanding window, the model is recursively estimated, while incrementing the window size one observation at a time. The first subsample includes the observations from the first observation 1 to the $j$ th observation we then extend each of the following subsample by adding one more observation than the previous one. Thus the last step estimation will be based on the whole sample.

Note that the size of the initial subsample can be selected arbitrarily as long as we only care about the result related with the later part of the data.

\subsection{Empirical Results}

\subsubsection{The Case of TUNINDEX}

\section{a- Graphic analysis}

The TUNINDEX is the main index of Tunis Stock Exchange contains 74 equities starting from 2014; it was launched on December 31.1997 with an initial base level of 1000. In order to be part of this index a company should be admitted in the capital market with minimum period of quotation of one month. Since 2009 the index has become a free float weighted index meaning that it is measured based on free float capitalization calculated by taking the equity's price and multiplying it by the number of shares available in circulation in the market instead of using all of the listed shares, this way it is able to provide a more accurate reflection of market movements.

\begin{tabular}{cccccc}
\hline Variable & Obs & Mean & Std. Dev. & Min & Max \\
\hline$y t$ & 130 & 3387.125 & $\mathbf{1 3 6 0 . 8 8 1}$ & $\mathbf{1 2 6 5 . 5 5 6}$ & $\mathbf{5 6 8 1 . 3 9}$ \\
\hline
\end{tabular}

Figure 1. Plots the time series trajectories of the Tunisian price index in the last 10 years

As the index grew steadily from the beginning of the sample, it witnessed ongoing fallout from the 14 January 2011 revolution due to serious demonstration of social unrest. Insecurity and the political process affected the mood of investors causing successive decreases in the market.

In 2012 activities on the stock exchange were marked by a positive trend with listed companies publishing positive reports, but hopes for recovery came to a sudden end when the US Embassy was attacked in September 2012 causing the index to drop steadily.

In 2013 the market started with miner progress that didn't last for long after the first Political assassination took place.

Later on with the designation of a new government in marsh the market freshened up a bit, but optimism was short-lived, with the country experiencing a second major crisis in July in the form of a second political assassination causing severe social protests that naturally affected the stock exchange activities. 


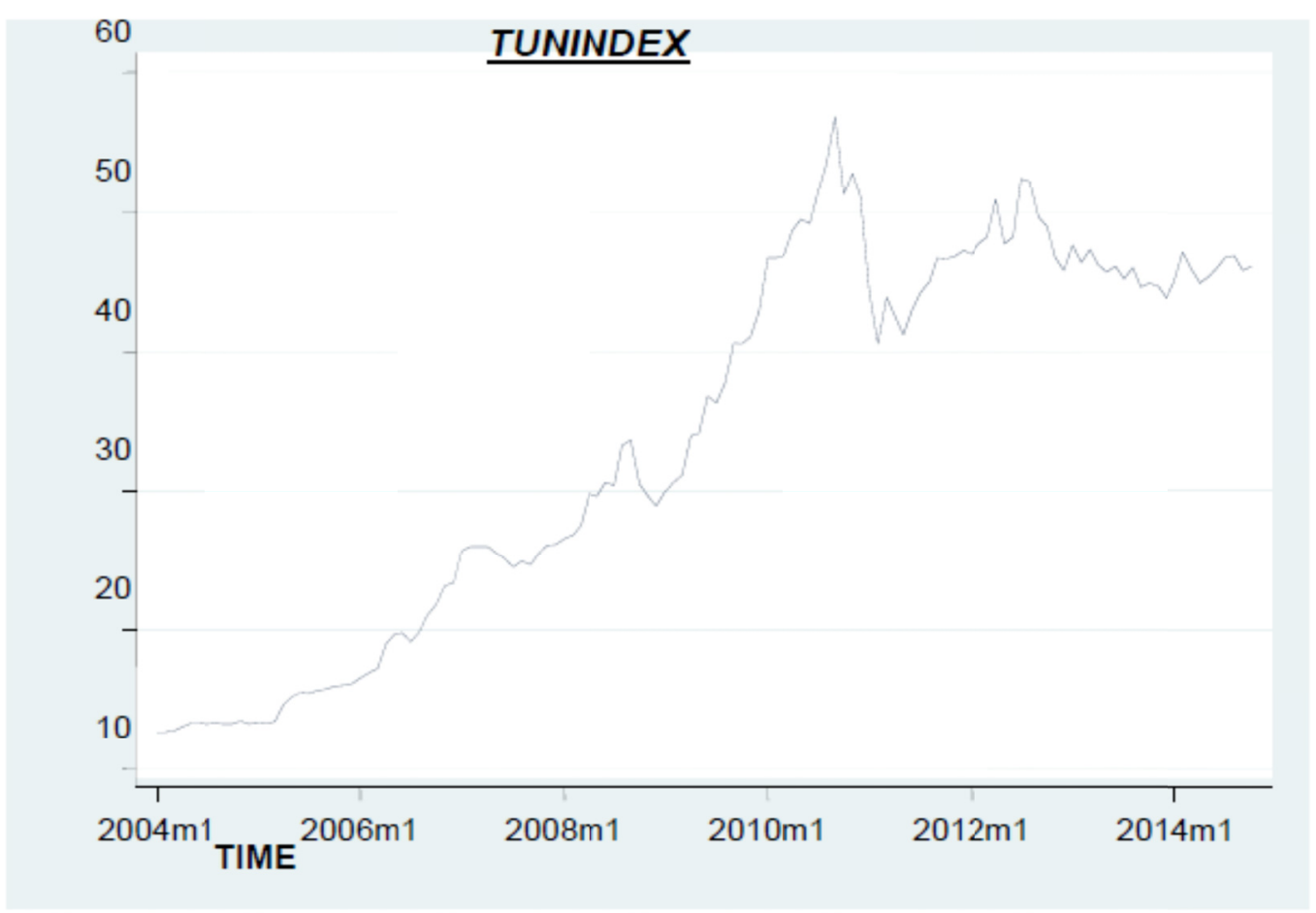

Figure 2. TUNINDEX evolution over the time

\section{b- CUSUM analysis}

In this study the CUSUM is calculated by using the Stata-module cusum 6 that calculates the recursive residuals from a time series regression in order to generate the CUSUM squared tests of structural stability.

The purpose is to test the existence of breaks. The underlying idea in CUSUM is to detect persistent changes or shifts in the underlying process.

In simple words, in CUSUM analysis we have three important values: the center line, which represents the target value, the upper control limit and the lower control limit. The test takes the cumulative sum of recursive residuals and plots its value against the upper and lower bounds of the $95 \%$ confidence interval at each point.

If the process is in control, it should stay between these two limits. Observations outside of the borders signal changes in the underlying process. 


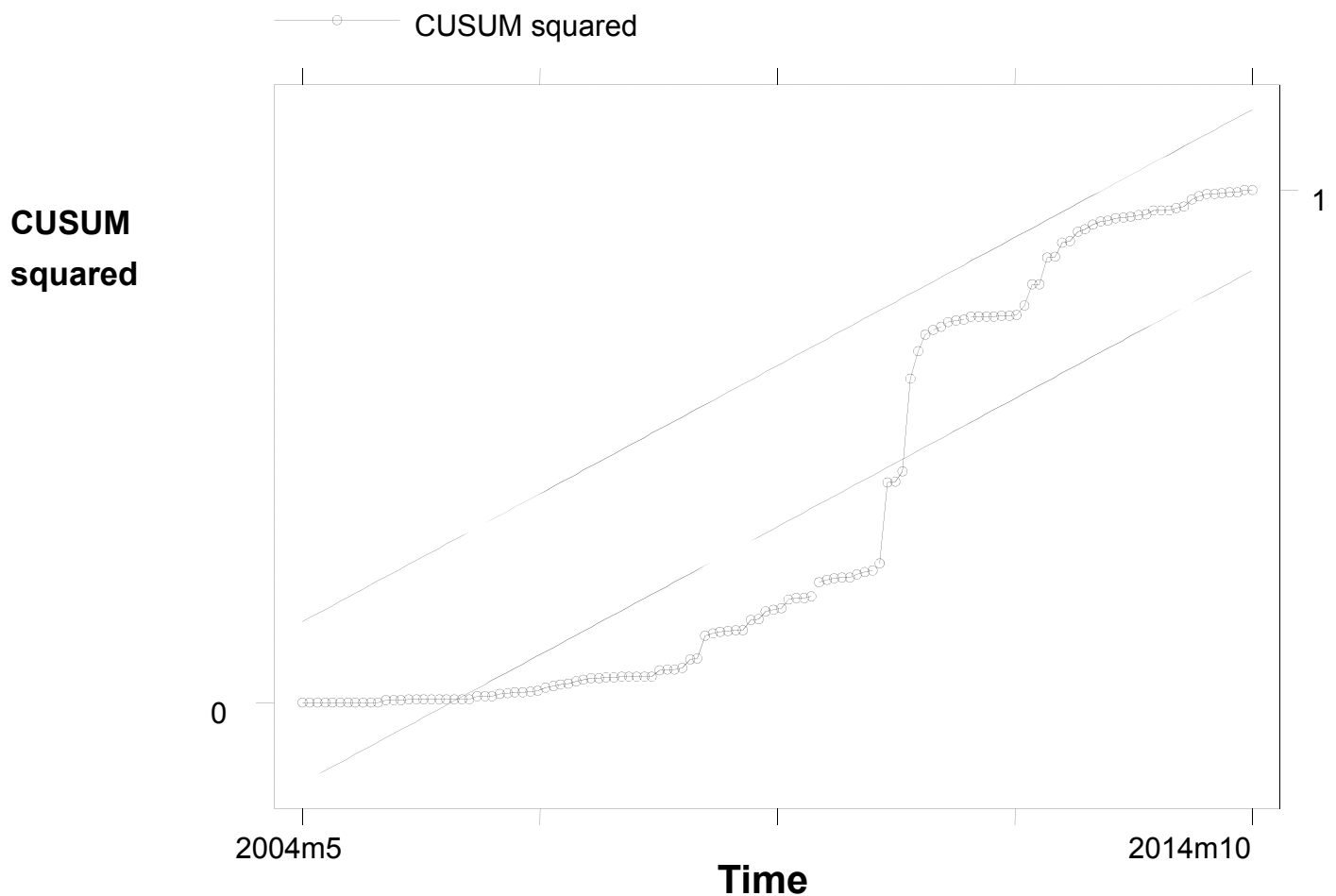

Figure 3. CUSUM test for the TUNINDEX

As suggested by the graph, parameter constancy may have broken down around the period from 2006 to 2011 . the fact that we have this many observations outside the limits indicate Very large shifts. The TUNINDEX process was clearly out of control at that time.

\section{c- Traditional ADF analysis}

Before starting the rolling ADF we start by running the traditional ADF. The results are reported in the following table.

Table 1. ADF test results

Interpolated Dickey fuller

\begin{tabular}{ccccc}
\hline & Test statistic & $1 \%$ Critical Value & $5 \%$ Critical Value & $10 \%$ Critical Value \\
TUNINDEX & $\mathbf{- 1 . 3 0 7}$ & $\mathbf{- 3 . 5 0 1}$ & $\mathbf{- 2 . 8 8 8}$ & $\mathbf{- 2 . 5 7 8}$ \\
\hline
\end{tabular}

If we were to look for stationnarity of this time series, we shall conclude that the model is non stationary, having the ADF statistic larger than the $5 \%$ Critical Values we cannot reject the null hypotheses of non stationnarity $(\rho=1)$ against the alternative hypotheses of stationnarity $(\rho<1)$.

But as mentioned earlier the distribution is skewed to the left and we are here not to test stationarity but to test the presence of bubbles in the market, so if we were to follow the convention and apply the ADF test to the full sample (JAN 2004 to OCT2014), the unit root test would reject the null hypothesis of a random walk in favor of the right-tailed alternative hypothesis of explosive behavior at the $5 \%$ level of significance. Hence we can conclude that the index does follow an explosive behavior.

Nonetheless this test is subject to the criticism leveled by Evans (1991) who argues that standard unit root tests for the full sample have difficulty in detecting periodically collapsing bubbles, therefore we pass to rolling and recursive tests. 


\section{d- Rolling analysis}

Moving on to the Rolling version of the ADF, we will be testing the null hypothesis of a unit root against the alternative of an explosive root.

A key question here relates to the choice of window length used in the rolling regressions, how to determine the best subsample size is an important work before rolling ADF tests are implemented.

In fact, the subsample data should not be too small, that is the statistical characteristics of the estimators will be poor, and problem such as bias of coefficients will become serious.

In their empirical application Phillips and al (2011) used rolling regressions with 77 observations out of a total of 380 observation of the NASDAQ stock index.

In order to provide indicators able to provide reliable and timely signals, the rolling data windows here are limited to lengths 25 observation that is about $20 \%$ of the full sample. Where the ADF statistic is calculated over a rolling window of 25 observations. During this particular procedure, the window's start and end point are incremented one step at a time and the rolling ADF statistic is the maximal ADF statistic estimated among all possible windows. The results are reported in the following table.

The CRITICAL VALUES (CV) are obtained by Monte Carlo simulation with 100000 replications. The detailed procedure taken from the article "Rolling ADF Tests: Detecting Rational Bubbles in Greater China Stock Markets" is like this: 1) for sample size of 25, we simulate 100000 AR (1) unit root time series each with a fixed constant term; 2) since ADF statistic has the same sampling distribution as the DF statistic, we then use the DF test to compute the corresponding ADF statistic for each simulated sample, where the null hypothesis for the DF test is that there is a constant term but no time trend; 3) at last, we find the percentiles listed in the table for the 100000 ADF statistics; 4) procedures 1)-3) are repeated for different sample size.

In the paper, we will be using the 95 percentile critical values to evaluate explosive evidence in recursive and rolling ADF tests:

Table 2. Rolling ADF results for LnTUNINDEX

\begin{tabular}{cc}
\hline & Rolling ADF \\
\hline Log TUNINDEX & 1,172964 \\
CV $\mathbf{9 5 \%}$ & $-0,0079$ \\
$\mathbf{9 7 , 5 \%}$ & 0,32 \\
$\mathbf{9 9 \%}$ & 0,7137 \\
\hline
\end{tabular}

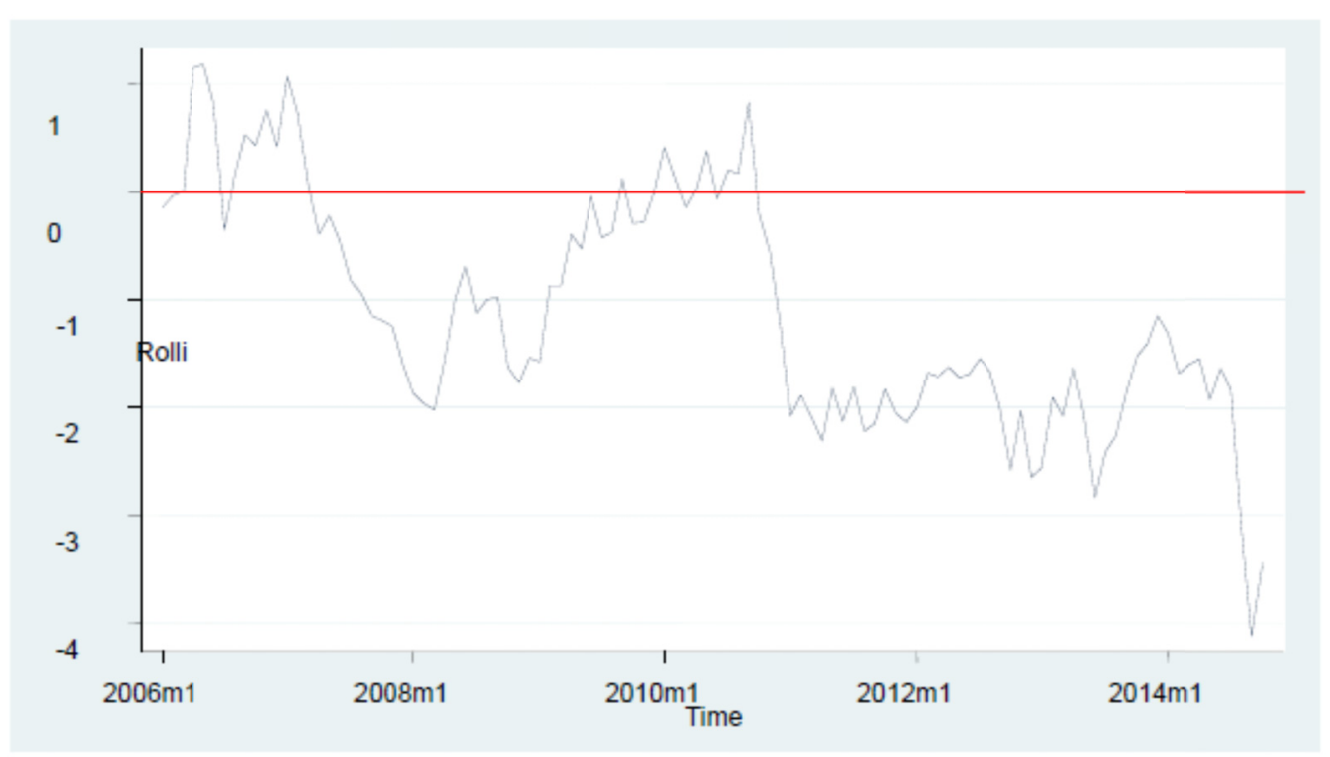

Figure 4. Rolling Dickey Fuller for LnTunidex 
The first thing to notice is that there is not only one bubble in the market. The ADF line don't just follow a clear trend and then drop sharply when the bubble burst, instead, they go up and down, then up and down again and again but each time in different degree.

The first occurrence date for price exuberance in the data is early 2006. The second one is in late 2010 not to mention periodically collapsing bubbles that lasts for a month or less.

The first bubble burst was in late 2007 consistent with the 2008 famous financial crisis, the second one was in late 2010 consistent with the Tunisian revolution.

What is remarkable is that even after the 2008 crisis, the market has been able to recover and prices rose again causing exuberance in the behavior of TUNINDEX again. But later in 2010, things seem to change radically, the exuberance started fading away after the revolution, this could be the results of a vigilant market, as investors' fears were fanned

by a pervasive climate of insecurity, nobody wants to invest nor gamble in a such a critical period of time, the changing in the investors mood was the reason why the market witnessed a massive selling which led prices to drop causing the bubble to burs.

The investors became more cautious, and speculation's returns were no longer tempting in such period of time where nothing was clear, this changing in the Tunisian mind set caused the bubble to burst and the behavior to change once and for all.

Another thing to notice is that since 2014 the curve fell sharply, the estimators are way smaller than the CV showing no sign of explosive process in prices, we conclude that nowadays, the market shows no sign of bubble like behavior which can be explained by the change in the mind set.

\section{e- Recursive analysis}

In forward recursive ADF tests, $\mathrm{ADF}$ statistic is computed for each recursive sub sample. The first subsample includes the observations from the first observation to the 25th observation.

As mentioned earlier the size of the initial subsample can be selected arbitrarily as long as we only care about the result related with the later part of the data.

The following table reports recursive $A D F$ tests of the null hypothesis of a unit root against the alternative of an explosive root, the recursive ADF statistic is the maximal ADF statistic estimated among all possible windows and the critical values for recursive ADF are the same as used earlier.

Table 3. RecursiveADF results for LnTUNINDEX

\begin{tabular}{cc}
\hline & \multicolumn{1}{c}{ Recursive ADF } \\
\hline Log TUNINDEX & 2,019281 \\
& CV for the explosive Alternative \\
$95 \%$ & $-0,0079$ \\
$97,5 \%$ & 0,32 \\
$99 \%$ & 0,7137 \\
\hline
\end{tabular}

The recursive test provides significant evidence of explosiveness in the price data at all the confidence levels, confirming the rolling conclusion of the presence of price exuberance in the Tunisian market. 


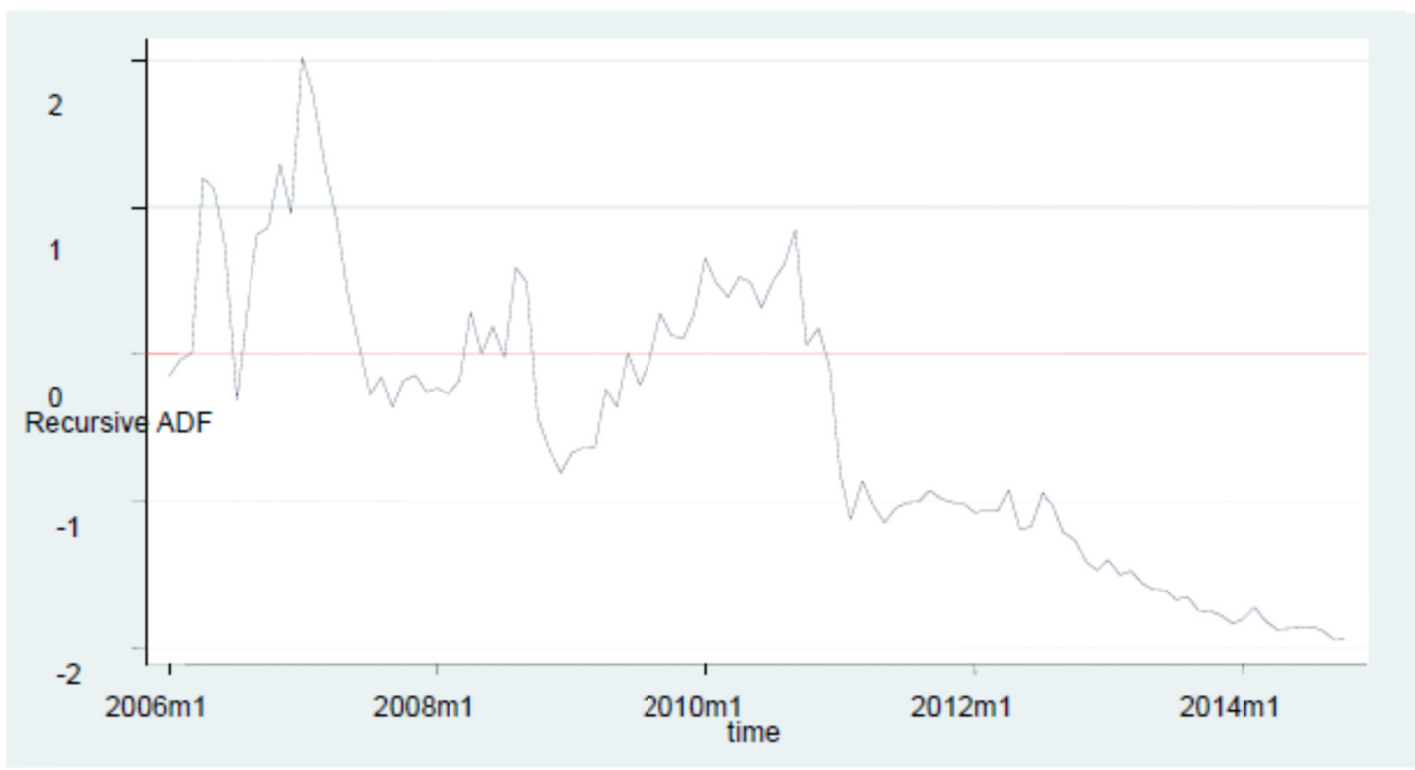

Figure 5. Recursive ADF for LnTUNINDEX

Several conclusion are drown from recursive ADF's curve; first it is clear that the recursive results are more or less consistent with the rolling results.

Interestingly other than the first bubble that crashed in late 2007, and the other one that crashed in late 2010 early 2011, the recursive test detects a third bubble, a small one that started right after the 2008 crisis and crashed just few months later.

Also consistent with the rolling test, the recursive curve confirms that after 2011 the market stopped showing any exuberance in the TUNINDEX behavior.

We can conclude that in this case, the recursive test seems to be more accurate and manages to detect bubbles with more precision.

\section{$f$ - Tunisian Vs Moroccan market}

In this section we will be investigating the Moroccan market by applying the same testing procedures on the MASI index.

MASI index (Moroccan All Shares Index) is a one of the two main stock index of the Casablanca Stock Exchange. It tracks the performance of all companies listed in.

Created in 31/12/1991 with an initial base level of 1000, MASI is also calculated based on the Free Float capitalization.

\begin{tabular}{llllll}
\hline Variable & Obs & Mean & Std. Dev. & Min & Max \\
\hline MASI & 2716 & 9557.13 & 2899.981 & 3806.15 & 14925.99 \\
& & & & & \\
\hline
\end{tabular}

The Curve below compares the Tunisian Index TUNIDEX to the Moroccan index MASI in the last critical 5 years. It shows that the Tunisian and the Moroccan market have different trajectories.

As mentioned earlier, after the revolution and the 2011 Crash, the change in the Tunisian investing mood led investors to back off and think twice before gambling with their money in a country of insecurity and political crisis where everything was blurry causing prices to decrease sharply in the Tunisian market. 
The same thing happened in the Moroccan market at that time, the country also witnessed few demonstrations, strikes and riots making the world think it is going to be another page in the book of Arabic Spring. Instead, the King offered some changing and some corrections hoping things will calm down, and indeed it did, Moroccans were pleased and the riot were over, interestingly, the market still suffers from a successive decreases in the prices since 2011 and it doesn't seem to recover well.

On the contrary the Tunisian market seem to sort of recover, even after the serious political turmoil of 2011 and the terrorist attacks of 2013, implying serious differences in mind set between the two countries. The Tunisian market shows more promising future comparing to its neighbor.

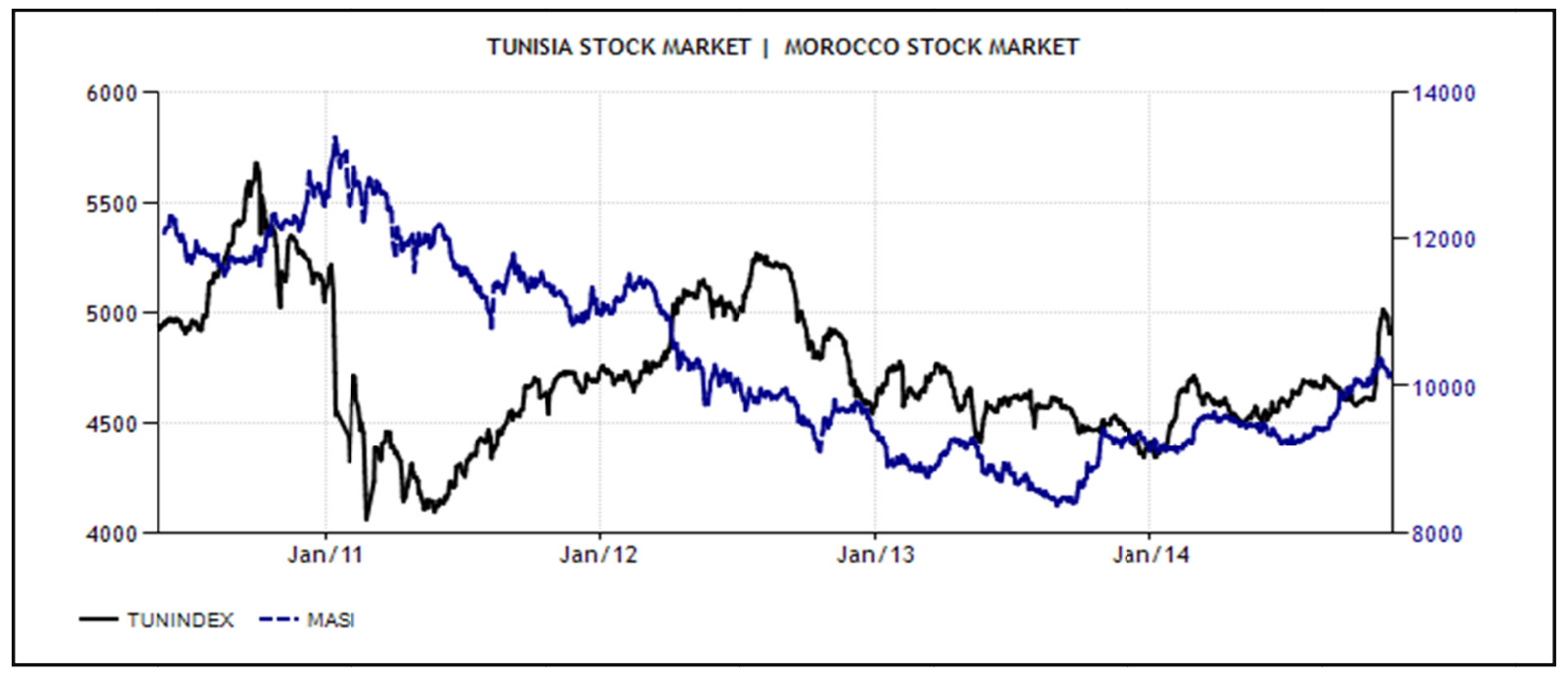

Figure 6. Comparing the TUNINDEX and MASI over the time

Applying the same technique on the Moroccan market, we used a subsample of 500 daily observations that is about $20 \%$ of the whole sample. As reported in the table below we also end up finding an explosive behavior in the time series.

Table 4. Rolling and Recursive ADF results for LnMASI

\begin{tabular}{lll}
\hline & RecursiveADF & Rolling ADF \\
\hline LogMASI & 2,502459 & 2,68656 \\
& & \\
& &
\end{tabular}

\section{CV for the explosive Alternative}

\begin{tabular}{ll}
$\mathbf{9 5 \%}$ & $-0,0736$ \\
$\mathbf{9 7 , 5 \%}$ & 0,2513 \\
$\mathbf{9 9 \%}$ & 0,6072 \\
\hline
\end{tabular}

Here, the two tests reject the null hypothesis of a random walk in favor of the right tailed alternative hypothesis at all the significance levels, accordingly we would conclude the significant existence of explosivenesses in the price data. 


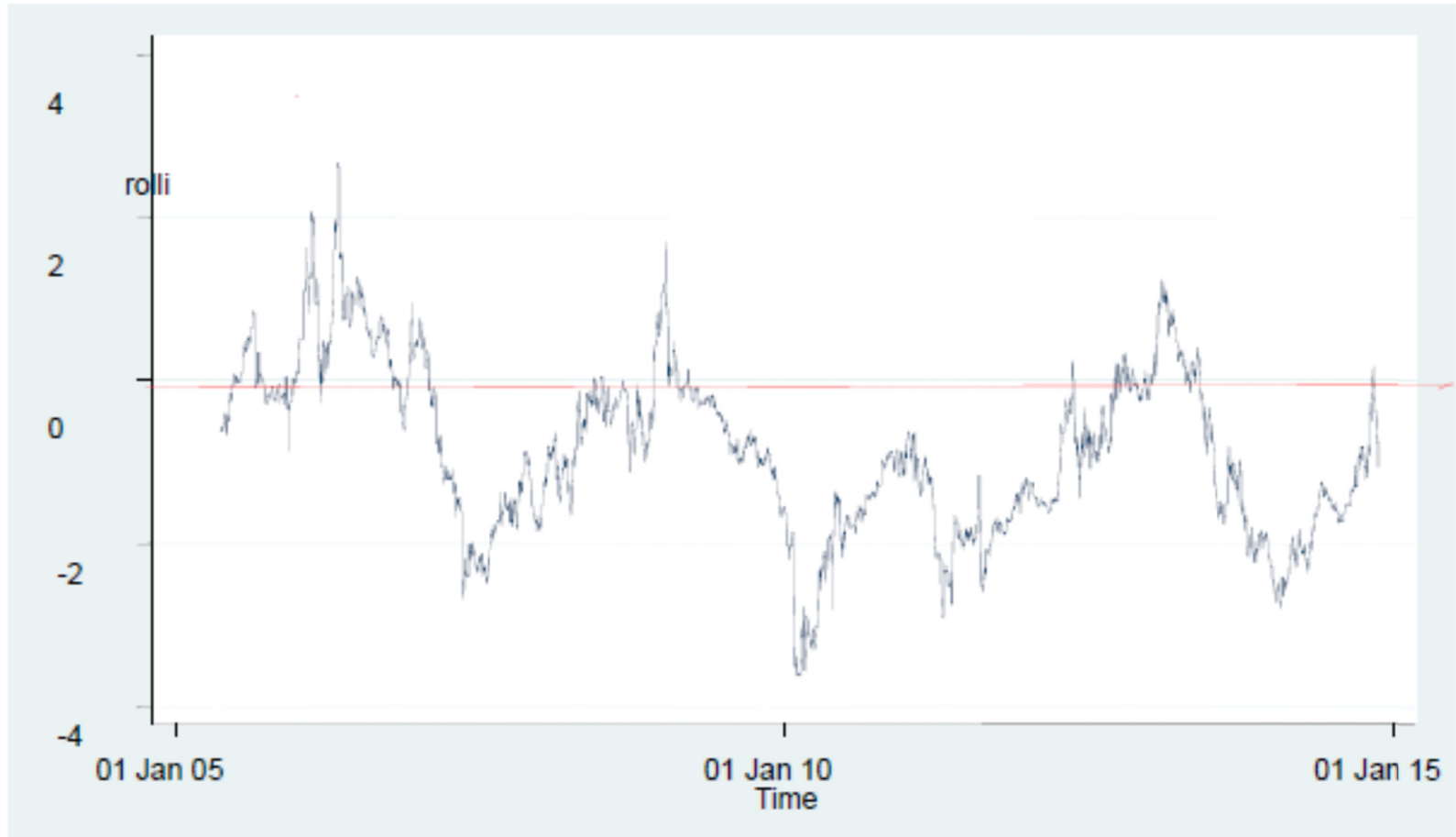

Figure 7. RollingADF for LnMASI

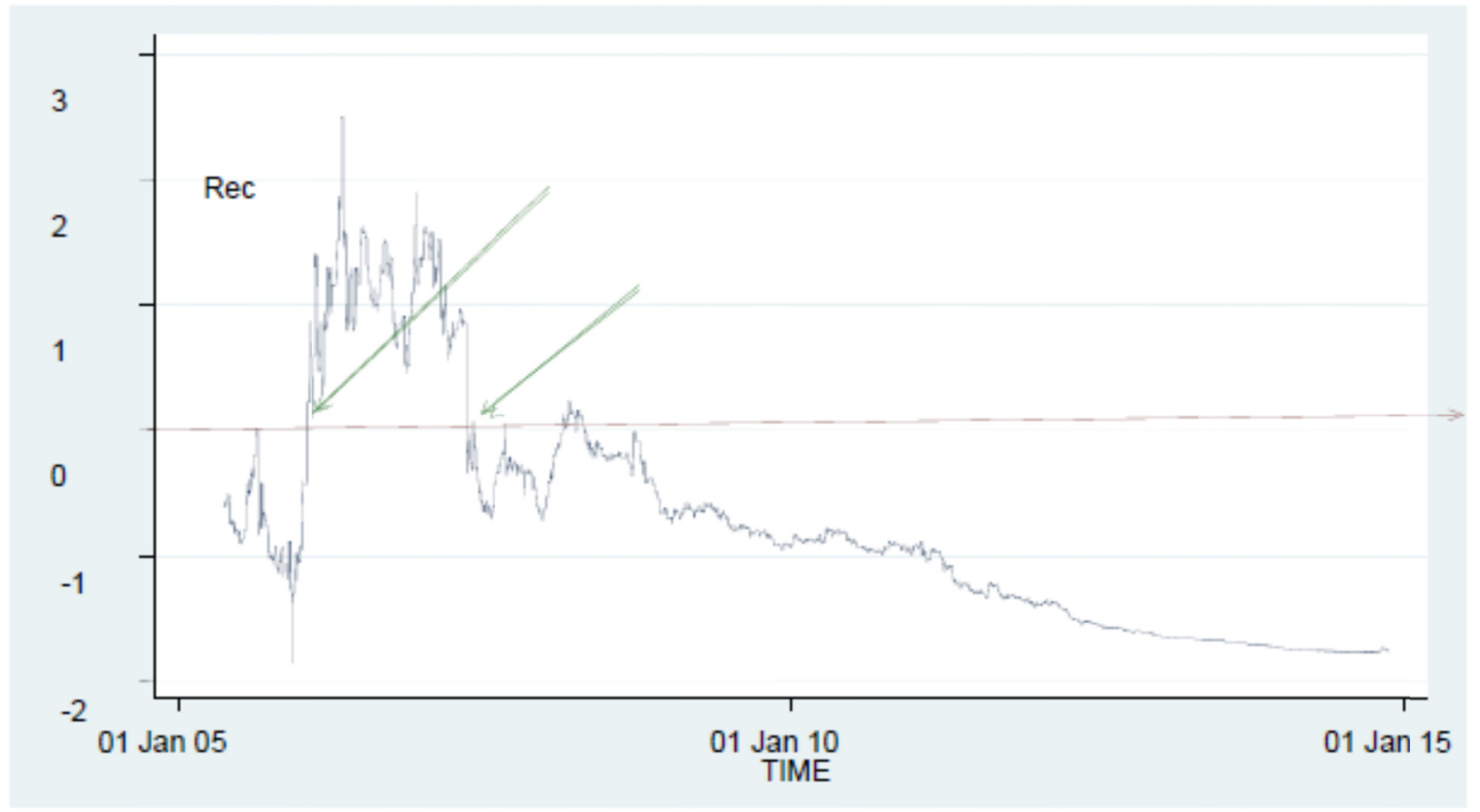

Figure 8. Recursive ADF for MASI

The Recursive technique only manages to detect one bubble that started in 2006 and crashed in late 2007, and then the market becomes stable. 
On the other hand the Rolling technique indicates the existence of 3 bubbles, one crashing in 2007, the other in 2009 and the last one is in late 2013, interestingly exuberance in the MASI's behavior doesn't last for a long period of time. As a matter of fact they only lasted for few months or less.

Unlike the Tunisian market, applying the rolling test to the Moroccan market seems to be more accurate than the recursive test.

Though Forward recursive ADF tests were quite capable in detecting NASDAQ bubble in the paper by Phillips and al. (2007), here it fails to detect bubbles with better accuracy. That might be because of the relatively large sample size (380 monthly observations) and smooth track of NASDAQ time series in one hand, and the small flexuous sample used in our test on the other hand.

\section{g- Limits of the tests}

When rolling and recursive ADF tests are implemented (in both markets) the lines of ADF statistics are almost all below the lines of the critical value.

Unlike the NASDAQ stock market tested in PWY (2011), the two markets in this paper do not have satisfying explosive form during the whole sample period,

This can be the result of the small sample employed here and the fact that the Tunisian and Moroccan markets are erratic and exhibits excessive volatility.

Actually, these markets were found to be non-efficient and non-dynamic making the sample used not smooth at all and very flexuous.

\subsubsection{The Case of 4 Particular Companies of the Tunisian Market}

We try to investigate the Tunisian market in this section by testing the behavior of 4 famous and well performing companies from 4 different sectors, that is MONOPRIX the retail corporation, SFBT for drinks industry, BANK of Tunisia and STAR for insurance.

We will be following the suggestion of Philips and all (2011) that stipulates "if the price is explosive while the dividend is non-explosive, there is evidence of bubble", So aiming to find evidence of bubble in the Tunisian market, in this section, not only we will be testing the price share but also the dividend distributed during the period from january2009 to December 2014.

Both the recursive and rolling ADF tests are applied to the datasets of both price series and Dividend Yield series for 1238 daily observation using subsamples of 150 in both tests. If the ADF statistic for index lies above the critical value and ADF statistic for the dividend yield lies below it, there is evidence of bubble according to the argument by Phillips and al. (2011). In other words, if the accelerating upswings in Price cannot be explained by only fundamental factors, then we have a Bubble.

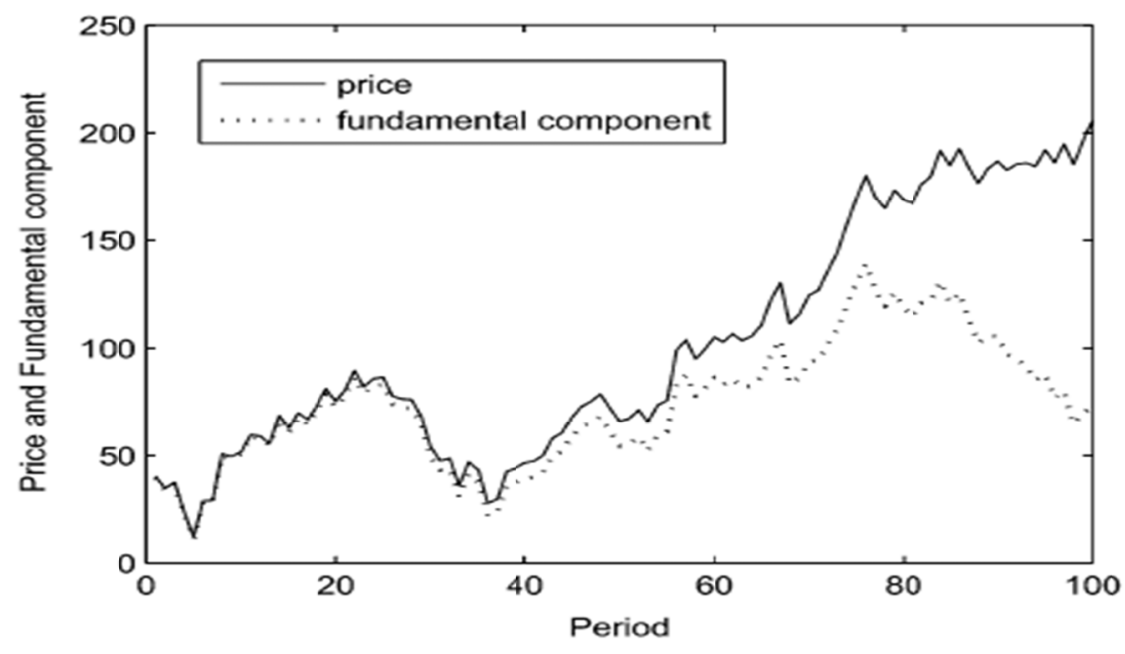

Figure 9. Simulated price series with a starting bubble 


\section{a- Rolling analysis}

Table 5. Rolling ADF results for the 4 selected companies

\begin{tabular}{cccccc}
\hline & \multicolumn{5}{c}{ Rolling ADF } \\
\hline & & BT & STAR & SFBT & MNP \\
& Log price & $\mathbf{3 , 1 2 9}$ & $\mathbf{1 , 5 9 2}$ & $\mathbf{3 , 3 4 4}$ & $\mathbf{2 , 9 3 9}$ \\
LV & Log dividend & $\mathbf{2 , 9 0 6}$ & $\mathbf{0 , 7 0 9}$ & $\mathbf{3 , 3 4 4}$ & $\mathbf{1 , 2 7 5}$ \\
\hline & & \multicolumn{4}{c}{$-\mathbf{0 , 0 7 3}$} \\
\end{tabular}

All the rolling results give strong evidence of explosiveness in Price and Dividend since the ADF statistic for both price and dividend series were all far exceeding the $95 \%$ critical Value we therefore reject the null hypotheses of a random walk in favor of explosive behavior in both series for all 4 companies.

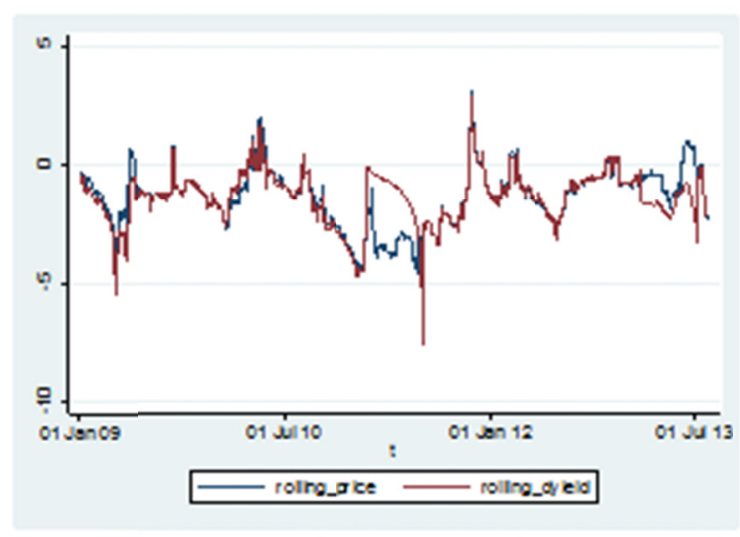

\section{Rolling BT}

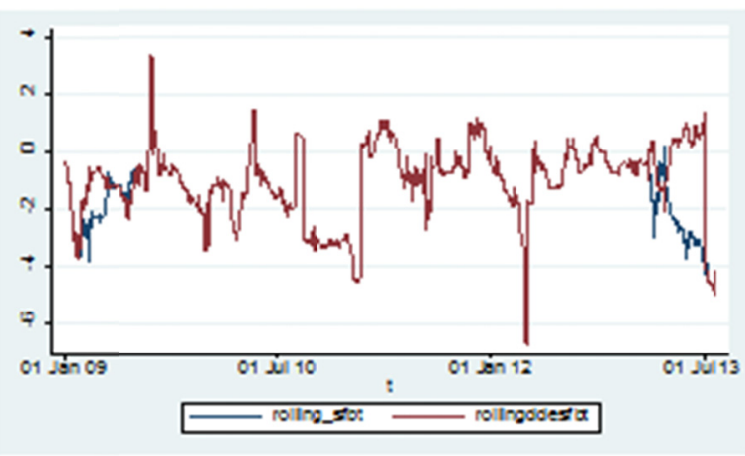

Rolling SFBT

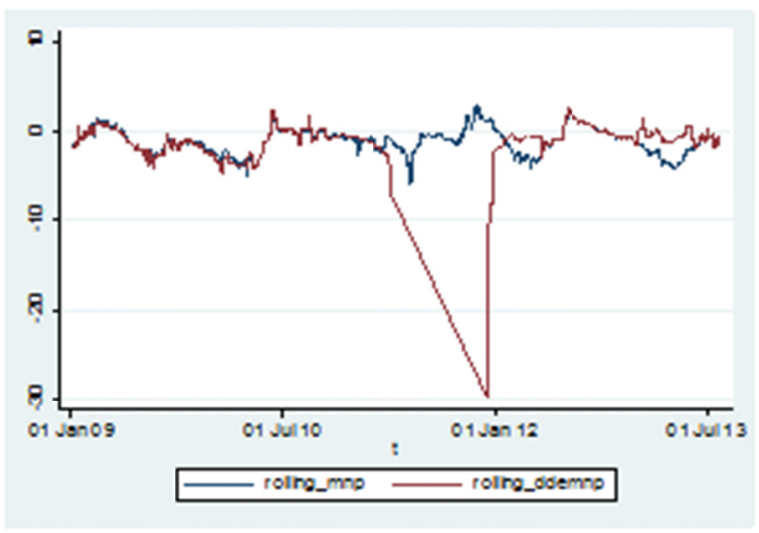

Rolling MNP

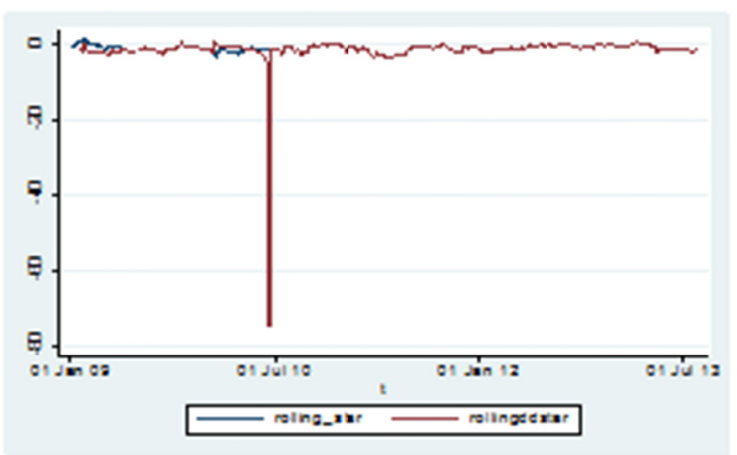

Rolling STAR

Figure 10. Rolling Plots for Dividend and Price series

Other than one obvious fell in the curve for MNP and STAR due to serious drop in the dividend distributed in 2010 for Star and in 2012 for MNP, the rolling curves for price and dividend are almost identical for all companies. This suggest that in most of the time, prices and dividends share the same behavior, thought it is an explosive one, we 
could not affirm the existence of a bubble since the upswings of Prices are in this case explained by fundamental factors that is dividend.

\section{b- Recursive analysis}

Table 6. Recursive ADF results for the 4 selected companies

\begin{tabular}{rrrccc}
\hline & \multicolumn{4}{c}{ Recursive ADF } \\
\hline & & BT & Star & SFBT & MNP \\
& Log price & $\mathbf{0 , 8 2 1}$ & $\mathbf{2 , 0 5 4}$ & $\mathbf{0 , 6 3 3}$ & $\mathbf{2 , 0 2 4}$ \\
& Log dividend & $\mathbf{0 , 5 6 0}$ & $\mathbf{1 , 3 7 2}$ & $\mathbf{0 , 6 9 4}$ & $\mathbf{1 , 3 9 6}$ \\
\hline
\end{tabular}

The recursive test presents the same results for all the companies in question meaning for both series of each company, we reject the null hypothesis of random walk in favor of the right-tailed alternative hypothesis of explosive process, we therefore confirm the significant evidence of exuberance in the behavior of both price and dividend series over the sample period. But still we could not affirm the existence of a bubble.

As concluded in the rolling analysis, the recursive test declare the 4 markets to be bubble free while the results applied on the TUNINDEX suggest the existence of few.

This dissimilarity in the results can be due to the fact that the tests are not so accurate when performed on small and flexuous sample, in fact when investigating the TUNINDEX the test period was about 11 years, though for the 4 companies the test period was only 5 years.

On the other hand, a visual inspection of the recursive graphs, only confirms the bubble free suggestion for MNP and SFBT, as for BT and STAR it suggest that in the beginning of the sample (first semester of 2009) the exuberance behavior of the price index was not backed with an exuberance in the fundamentals behavior.

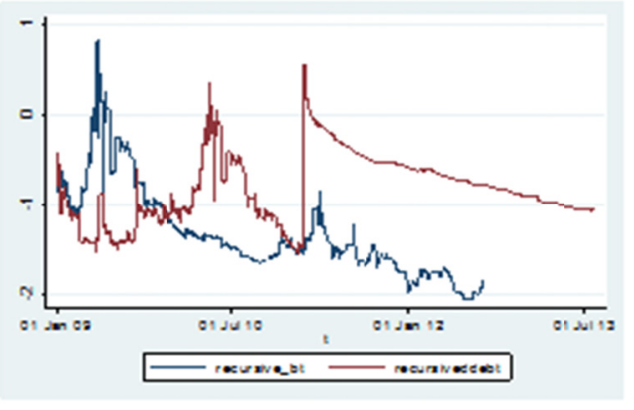

Recursive BT

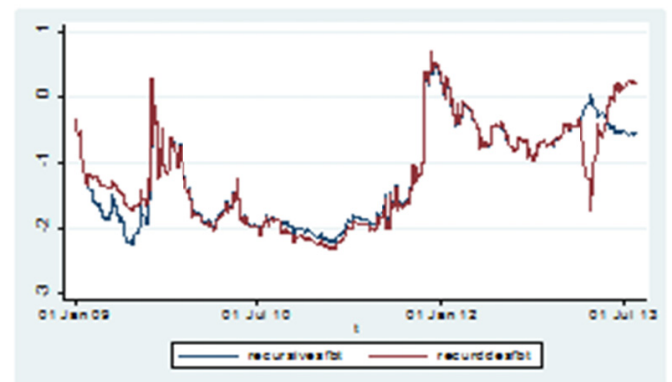

Recursive SFBT

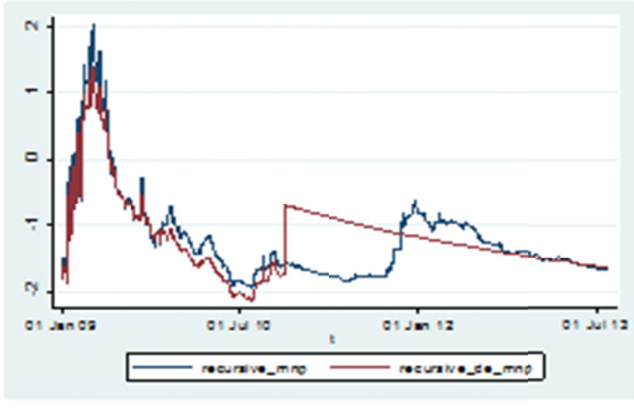

Recursive MNP

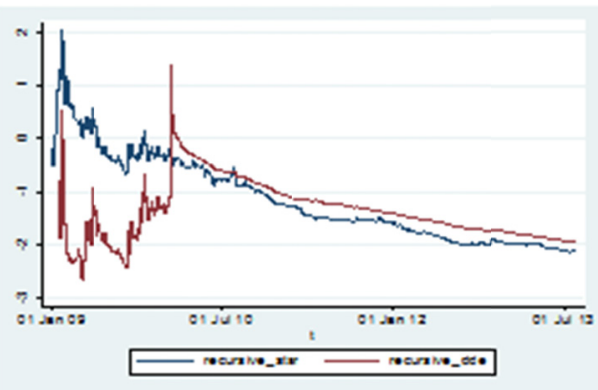

Recursive STAR

Figure 11. Rolling Plots for Dividend and Price series 


\section{Conclusion}

The past few years have seen an unprecedented increase in speculative activities. While the exact tools remain controversial, the negative impact is not doubtful. This thesis attempts to explain speculation, what it actually is and what it is not.

It is true that speculation is useful in providing liquidity for the market, The problem lies in the excessive level of speculation that bring no benefit to the public.

Not to confuse it with hedging or investment, speculation can seriously play a deep and significant role in destabilizing the market; not only it fails to contribute to creating added value and developing the economy, it can also manipulate the market by driving prices up and down, increasing market volatility more than it already is and creating bubbles.

Though each bubble is in its own way different, the results are the same: speculation, boom, more speculation, crash, and then the financial pain.

The empirical application of our thesis involves testing for the presence of bubbles in the Tunisian market, following Phillips and all 2011, finding an explosive behavior in prices is what leads to admitting the existence of the bubble.

When testing for the said behavior in the TUNINDEX, we make use of rolling and recursive regression and the findings confirms the existence of exuberance in the Tunisian market, comparing the findings with the Moroccan case shows similar exuberance but on different period of time.

However, when examining 4 particular firms listed on the Tunisian market, we find different results, the results explain how in these 4 cases, the explosiveness in prices can be baked with explosiveness in dividend hence showing no sign for a bubble.

It should be noted that this work has not attempted to identify explicit sources of the found exuberance nor it date stump the exact origination and collapse of the found bubbles.

Last but not least it is crucial to mention that despite the harm done by speculation, attempting to ban it would be absurd. Nonetheless its negative impact can be smoothed by markets regulation. That means making the markets less attractive for short seller and greedy investors by reducing the hoped-for returns, increasing access costs, reducing the easy access to debt and financial innovation and imposing Taxes on short selling.

\section{References}

Ahamed. (2009). Lords of Finance: The Bankers Who Broke the World. Penguin Press, New York.

Álvaro, J. (2011). Understanding Economic Bubbles. Economica.

Behzard \& Grossman. (1984). Rational Bubbles in the Price of Gold. NBER Working Papers 1300, National Bureau of Economic Research.

Bernardina, A. (2012). Price Volatility, Speculation and Excessive Speculation in Commodity Markets: sheep or shepherd behavior?. ZEF- Discussion Papers on Development Policy No. 166.

Blanchard, O. J. (1979. Nov.). Speculative bubbles, crashes and rational expectations. Economics Letters, 3, 387-389.

Deuskar \& Johnson. (2011). Market Liquidity and Flow-Driven Risk. Review of Financial Studies.

Diba \& Grossman. (1988). Explosive rational bubbles in stock prices?. The American Economic Review, 78, 520-530.

Evans. (1991). Pitfalls in testing for explosive bubbles in asset prices. The American Economic Review, 81, 922-930.

Fridson, M. (1993). Exactly What do You Mean by Speculation?. The Journal of Portfolio Management, 20(1).

Froot \& Obstfeld. (1991). Intrinsic bubbles: The case of stock prices. American Economic Review, 81, 1189-1214.

Hamilton \& Whiteman. (1985, November). The Observable Implications of Self-Fulfilling Expectations. Journal of Monetary Economics, 16, 353-73.

Harrison \& Kreps. (1978). Speculative investor behavior in a stock market with heterogeneous expectations. The quartly journal of economics, 192(2).

Kenneth \& Mccrachen. (1998). Regression-Based Tests of Predictive Ability. NBER Technical Working Papers 0226, National Bureau of Economic Research. 
Kindleberger. (1987). Bubbles. The New Palgrave: A Dictionary of Economics, John Eatwell, Murray Milgate, and Peter Newman, (Eds.). New York: Stockton Press, 281.

Phillips, B, Wu, Y, \& Yu, J. (2011). Explosive behavior in the 1990s NASDAQ: When did exuberance escalate asset values?. International economic review, 52(1).

Shiller. R. J. (1981). Do stock prices move too much to be justified by subsequent changes in dividends?. The American Economic Review, 71, 421-436.

Shiller. R. J. (2000). Irrational Exuberance. Princeton University Press.

West, K. (1987). A Specification Test for Speculative Bubbles. Quarterly Journal of Economics, 102, 553-80.

Appendix 1

1. Simulated AR (1) model with $\rho=0.8$ (sample size is 200)

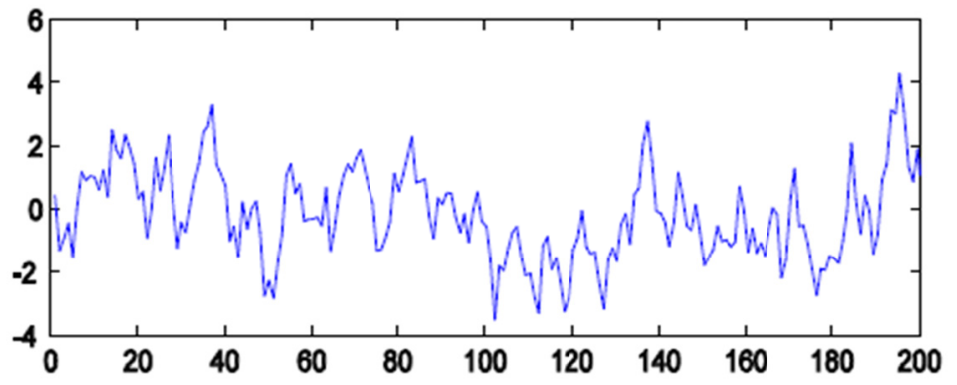

A stationary process with mean 0 and variance less than infinity

2. Simulated AR (1) model with $\rho=1$ (sample size is 200)

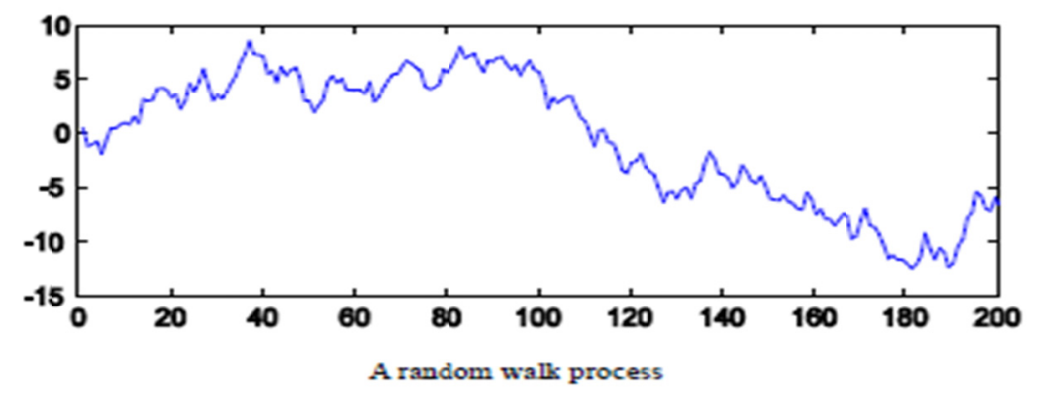

3. Simulated AR (1) with $\rho=1.03$ (sample size is 200 )

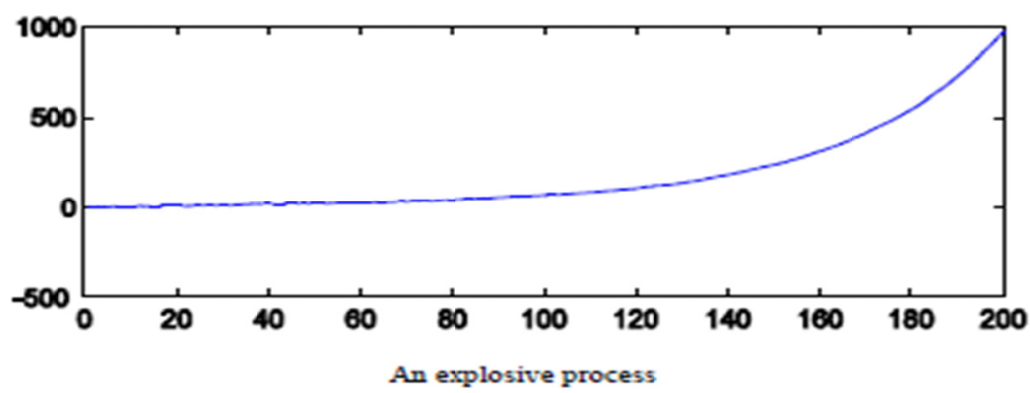

Figure 1. Typical stationary, random walk, and explosive autoregressive trajectories 
Table 1. Monte Carlo simulated Critical Value for ADF statistics

\begin{tabular}{|c|c|c|c|c|c|c|c|c|}
\hline & $\mathbf{0 . 0 1}$ & $\mathbf{0 . 0 2 5}$ & $\mathbf{0 . 0 5}$ & $\mathbf{0 . 1}$ & $\mathbf{0 . 9}$ & $\mathbf{0 . 9 5}$ & $\mathbf{0 . 9 7 5}$ & $\mathbf{0 . 9 9}$ \\
\hline $\mathbf{2 5}$ & -3.7417 & -3.3249 & -2.9947 & -2.6415 & -0.3763 & -0.0079 & 0.32 & 0.7137 \\
\hline $\mathbf{3 0}$ & -3.6743 & -3.2889 & -2.9593 & -2.6155 & -0.3912 & -0.0258 & 0.3057 & 0.6873 \\
\hline $\mathbf{3 5}$ & -3.6442 & -3.2662 & -2.9525 & -2.6169 & -0.3948 & -0.0211 & 0.2984 & 0.6704 \\
\hline $\mathbf{4 0}$ & -3.6172 & -3.2383 & -2.9385 & -2.613 & -0.3987 & -0.0376 & 0.2865 & 0.6692 \\
\hline $\mathbf{4 5}$ & -3.594 & -3.2332 & -2.93 & -2.6067 & -0.4075 & -0.0346 & 0.2898 & 0.6848 \\
\hline $\mathbf{5 0}$ & -3.5694 & -3.2283 & -2.9326 & -2.601 & -0.4033 & -0.0383 & 0.2849 & 0.6669 \\
\hline $\mathbf{5 5}$ & -3.5641 & -3.2008 & -2.9145 & -2.5977 & -0.4062 & -0.0367 & 0.2775 & 0.6544 \\
\hline $\mathbf{6 0}$ & -3.5484 & -3.1972 & -2.9127 & -2.5952 & -0.4146 & -0.0553 & 0.2738 & 0.6329 \\
\hline $\mathbf{1 0 0}$ & -3.515 & -3.1668 & -2.8862 & -2.5784 & -0.4274 & -0.0563 & 0.2595 & 0.6348 \\
\hline $\mathbf{1 5 0}$ & -3.4582 & -3.1369 & -2.8758 & -2.5763 & -0.4313 & -0.073 & 0.2483 & 0.6264 \\
\hline $\mathbf{5 0 0}$ & -3.4254 & -3.1214 & -2.8609 & -2.5598 & -0.4334 & -0.0736 & 0.2513 & 0.6072 \\
\hline $\mathbf{2 0 0 0}$ & -3.4398 & -3.1316 & -2.8724 & -2.5689 & -0.4442 & -0.0741 & 0.241 & 0.5979 \\
\hline
\end{tabular}

